\title{
FORCED OSCILLATION OF SECOND-ORDER NONLINEAR FUNCTIONAL DYNAMIC EQUATIONS ON TIME SCALES
}

\author{
H.A. Agwa, Ahmed M.M. Khodier and Heba M. Atteya
}

Abstract. In this paper, we establish some new oscillation criteria for the second-order nonlinear functional dynamic equation with forced term

$$
\left(r(t) x^{\Delta}(t)\right)^{\Delta} \pm p(t) f(x(\tau(t)))=e(t),
$$

on a time scale $\mathbb{T}$. No restriction is imposed on the forcing term $e(t)$ to satisfy the Kartsatos condition. $p(t)$ and $r(t)$ are real-valued rd-continuous functions defined on $\mathbb{T}$. There are many cases have been taken into consideration: (i) $p(t)>0, \tau(t) \leqslant t(\geqslant t)$ and $\tau(t) \leqslant \sigma(t)(\geqslant \sigma(t))$ (ii) $p(t)$ changes its sign, $\tau(t) \leqslant t(\geqslant t), \tau: \mathbb{T} \rightarrow \mathbb{T}$ is a strictly increasing differentiable function and $\lim _{t \rightarrow \infty} \tau(t)=\infty$. Our results not only generalize and extend some existing results but also can be applied to the oscillation problems that are not covered in literature. Finally, we give some examples to illustrate our main results.

Mathematics subject classification (2010): 34C10, 34K11, 39A10.

Keywords and phrases: oscillation, forced second order delay dynamic equations, time scales..

\section{REFERENCES}

[1] M. Bohner, A. Peterson, Dynamic Equations on Time Scales: An Introduction with applications, Birkhüser, Boston, 2001.

[2] M. Bohner, A. Peterson, Advances in Dynamic Equations on Time Scales, Birkh ä user, Boston, 2003.

[3] M. Bohner, C.TISDelL, Oscillation and nonoscillation of forced second order dynamic equations, Pacific J. Math., 230 (2007), 59-71.

[4] L.H. Erbe, B. Karpuz, A.C. Peterson, Kamenev-type oscillation criteria for higher-order neutral delay dynamic equations, Int. J. Difference Equ., 1 (2011), 1-16.

[5] G.H. Hardy, J.E. Littlewood, G. Pólya, Inequalities, Cambridge Mathematical Library, Cambridge University Press, Cambridge, UK, 1988.

[6] S. HiLger, Analysis on measure chains - A unified approach to continuous and discrete calculus, Results Math., 18 (1990), 18-56.

[7] M. HuAnG, W. FENG, Oscillation for forced second order nonlinear dynamic equations on time scales, Electronic Journal of Differential Equations, 145 (2006), 1-8.

[8] M. HuAng, W. Feng, Forced oscillation of second order nonlinear dynamic equations on time scales, Electronic Journal of Qualitative Theory of Differential Equations, 36 (2008), 1-13.

[9] T.X. LI, Z.L. HAN, S.H. SUN, C.H. ZHAN, Forced oscillation of second-order nonlinear dynamic equations on time scales, Electronic Journal of Qualitative Theory of Differential Equations, 60 (2009), 1-8. 
[10] S.H. SAKER, Oscillation of second-order forced nonlinear dynamic equations on time scales, Electronic Journal of Qualitative Theory of Differential Equations, 23 (2005), 1-17.

[11] Yuangong Sun, Forced oscillation of second-order superlinear dynamic equations on time scales, Electronic Journal of Qualitative Theory of Differential Equations, 44 (2011), 1-11.

[12] Y. Sun, Z. HAN, On forced oscillation of higher order functional differential equation, Appl. Math. Comput., 218 (2012), 6966-6971.

[13] P. G. WANG, N. TANG, C. X. GAO, Oscillation of forced second order dynamic equations on time scales, Advances in Dynamical Systems and Applications, 4 (2009), 123-131. 